\title{
A Comparitive Study of Chlorhexidine Alcohol versus Povidone- Iodine for Pre-operative Skin Preparation
}

\author{
P Murugadasan $^{1}, \mathrm{G}_{\text {Mahadevi }}^{2}$ \\ ${ }^{l}$ (Assistant Professor, Department Of General Surgery, Government Medical College Hospital, \\ Coimbatore,Tamilnadu, India) \\ ${ }^{2}$ (Junior Resident,Department Of General Surgery, Government Medical College Hospital, \\ Coimbatore,Tamilnadu, India)
}

\begin{abstract}
Surgical site infections are defined as infections of organs, tissues or organ spaces which are handled by operating surgeons at the time of surgical procedure. Since patient skin is an important source of pathogens that cause SSIs, optimization of skin prior to surgery with skin antisepsis may decrease the postoperative infection in clean and clean contaminated surgeries. There are many varieties of antiseptic materials available for preoperative skin preparation, however Povidone iodine and chlorhexidine alcohol are widely used in clinical practice. We conducted a prospective study to compare the efficacy of chlorhexidine and povidone iodine in preventing surgical site infection after clean and clean contaminated elective surgery in patients admitted to general surgical ward in Coimbatore Medical College Hospital between August 2015 and August 2016.The study found out that preoperative cleansing the wound with chlorhexidine alcohol is superior to povidone iodine in preventing surgical site infection.
\end{abstract}

Keywords: chlorhexidine alcohol, efficacy, povidone iodine, skin preparation, surgical site infection,

\section{Introduction}

Surgical site infections(Fig:1) are defined as infections of organs, tissues or organ spaces which are handled by operating surgeons at the time of surgical procedure. Surgical site infections [SSIs] is till now sustained as a major problem for operating surgeons even with significant improvements in antibiotics, anaesthesia techniques, good quality instruments. Since patient skin is an important source of pathogens that cause SSIs,optimization of skin prior to surgery with skin antisepsis may decrease the postoperative infection in clean and clean contaminated surgeries. There are many varieties of antiseptic materials available for preoperative skin preparation however Povidone iodine and chlorhexidine alcohol are widely used in clinical practice.

\section{Aims And Objectives}

To know whether povidone iodine or chlorhexidine alcohol as preferred agent for cleansing of skin prior to clean and clean contaminated elective surgeries in a Tertiary care center in Coimbatore.

\section{Materials And Methods}

A comparative study on surgical site antisepsis was done over a 12 month period.Among the patients admitted to general surgical ward in Coimbatore Medical College Hospital ,those who were posted for clean and clean contaminated elective surgeries over 12 months were included in this study.Sample size was 120. Type of sampling was purposive sampling and randomization was simple.The patients were grouped into two categories that is Group A (Chlorhexidine alcohol group), Group B (Povidone iodine group).The antiseptic agents were applied to the skin by sterile gauze under aseptic precautions(Fig:2). The antiseptics were left in the skin for 3-4 minutes.The surgical wound were examined on postoperative day $3,5 \& 7$ for any infections present to check for surgical site infections as per the Joint Commission guidelines. Subject were followed up weekly for a period of 30 days. Data was analysed using SPSS Software Version17. Descriptive statistics are reported using mean, median and SD for continuous variables, number and percentages for categorical variables. Logistic regression was used to find the predictors for mortality. Probability value less than 0.05 was considered statistically significant.

\section{Results}

During the study period from August 2015 to August 2016, we had 120 patients, 60 of them preoperatively prepared with Chlorhexidine Alcohol and 60 with Povidone iodine. Mean age in group using chlorhexidine alcohol is $44.11 \pm 15.3$ and mean age in group using povidone iodine is $42.37 \pm 15.6$. In group using chlorhexidine alcohol male constitutes $41.7 \%$ and female constitutes $58.3 \%$. In group using povidone iodine male constitutes $51.7 \%$ and female constitutes $48.3 \%$. In group using chlorhexidine alcohol clean 
surgeries constitutes $76.7 \%$ and clean contaminated surgeries constitutes $23.3 \%$.In group using povidone iodine clean surgeries constitutes $80 \%$ and clean contaminated surgeries constitute $20 \%$. In group using chlorhexidine alcohol General anesthesia constitutes $60 \%$ and Regional anesthesia constitutes $40 \%$. In group using povidone iodine clean surgeries general anesthesia constitutes $56.7 \%$ and regional anesthesia constitutes $43.3 \%$. Surgical site infections (SSI) were found to be positive in $19.2 \%$ cases in the study. Type of organisms found in the study are E.Coli $(2.5 \%)$, Klebsiella(3.3\%), Pseudomonas(0.8\%), Staphylococcus $(11.7 \%)$ and Streptococcus constitutes $(0.8 \%)$. Type of organisms among gender in the study are E.Coli is present in 2 males and 1 female, Klebsiella in 4 females, Pseudomonas 1 male, Staphylococcus is present in 7 males and 7 females, Streptococcus in 1 male in the study. Type of organisms with nature of surgery are, E.Coli in 3 clean contaminated surgeries, Klebsiella in 1 clean surgeries and 3 in clean contaminated surgeries, Pseudomonas in 3 clean contaminated surgeries, Staphylococcus in 4 clean surgeries and 10 clean contaminated surgeries, Streptococcus in clean contaminated surgeries in the study. Association of using chlorhexidine alcohol and povidine iodine agents with the presence of surgical site infections (SSI) was found using Chi square test .The presence of surgical site infections (SSI) in the study using chlorhexidine alcohol was only $8.3 \%$ and using Povidone Iodine was $30 \%$ and the difference was found to be statistically significant(p value 0.003) (Fig:3, TABLE:1). The presence of surgical site infections (SSI) in clean contaminated surgeries was $34.6 \%$ and that in clean surgery was $14.9 \%$ and the difference was found to be statistically significant(p value 0.024)(Fig:4,TABLE:2). Association of gender, type of anesthesia with surgical site infections were found to be not statistically significant.

Figures And Tables

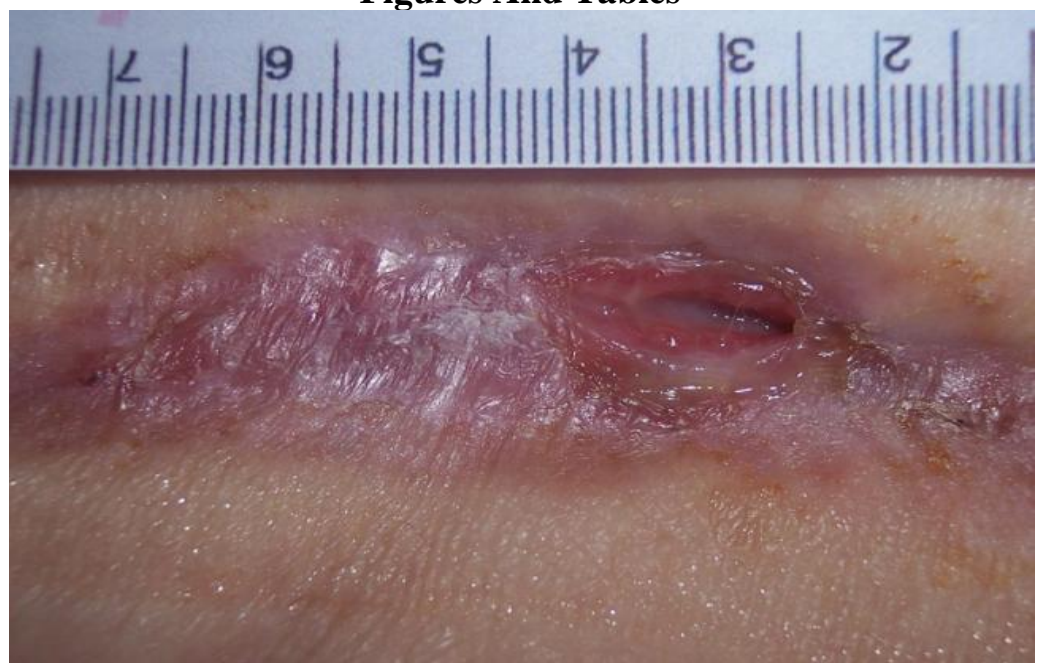

Figure:1 Surgical Site Infection

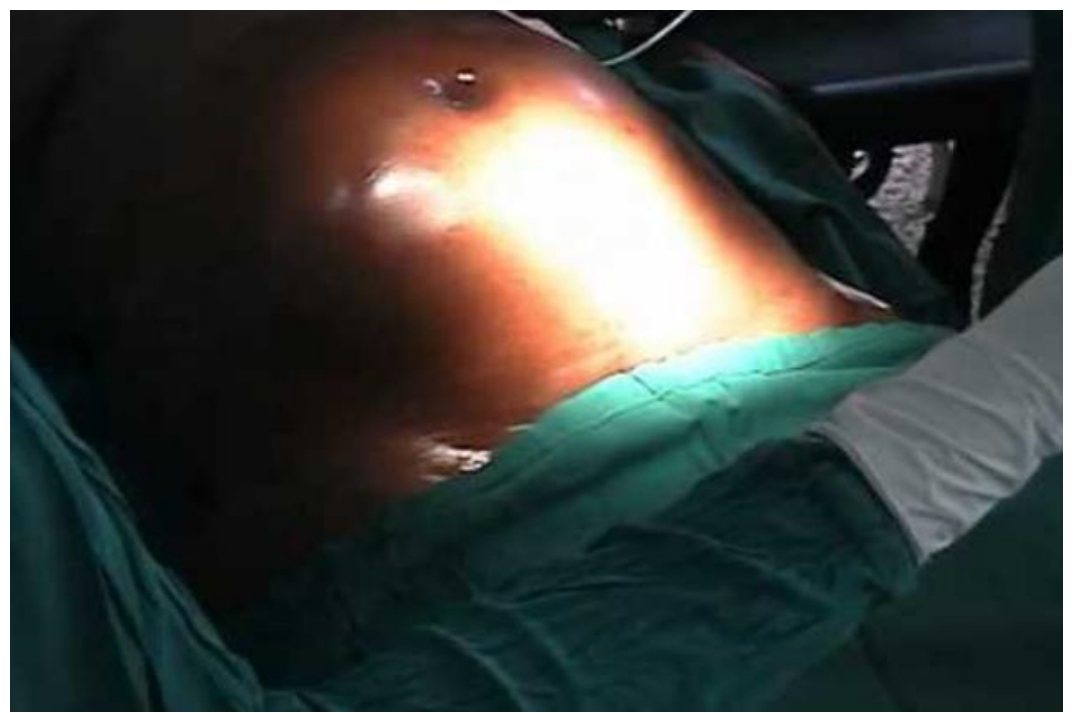

Figure :2 Painting with Antiseptic Agent 


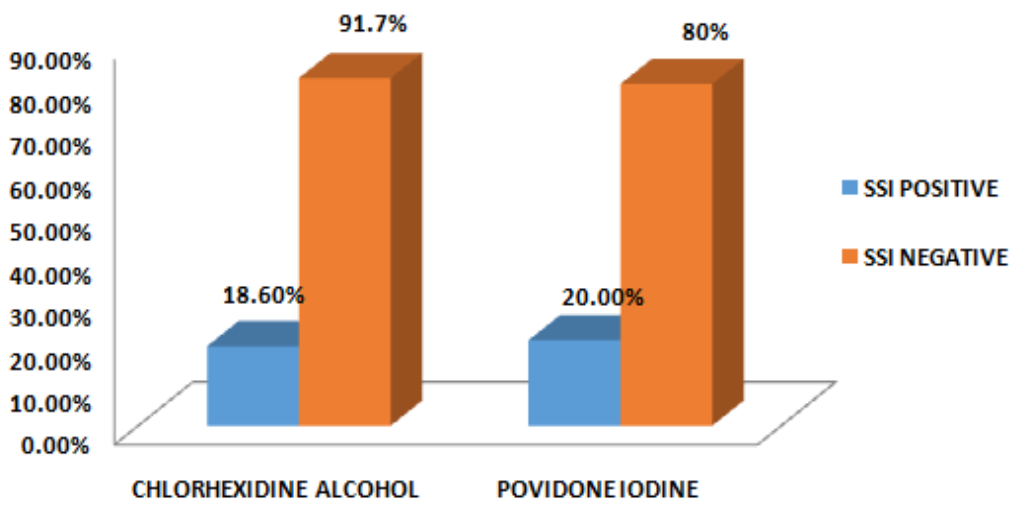

Figure:3

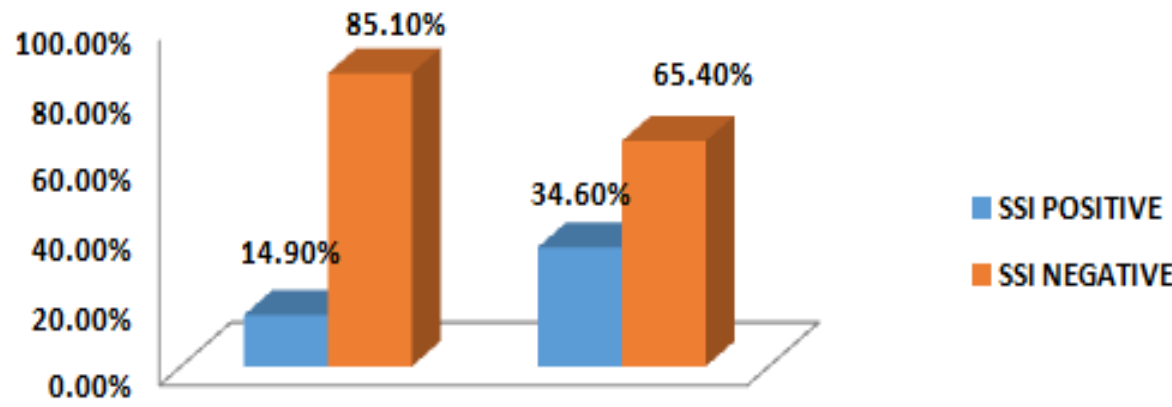

CLEAN SUGEREEAN CONTAMINATED SURGERIES

Figure:4

Table: 1

\begin{tabular}{|l|l|l|l|}
\hline STUDY GROUP & $\begin{array}{l}\text { SURGICAL SITE } \\
\text { INFECTIONS (SSI) } \\
\text { POSITIVE }\end{array}$ & $\begin{array}{l}\text { SURGICAL SITE } \\
\text { INFECTIONS (SSI) } \\
\text { NEGATIVE }\end{array}$ & P VALUE \\
\cline { 1 - 2 } $\begin{array}{l}\text { CHLORHEXIDINE } \\
\begin{array}{l}\text { ALCOHOL } \\
(\mathrm{N}=60)\end{array}\end{array}$ & $5(8.3 \%)$ & $55(91.7 \%)$ & $.003 *$ \\
\cline { 1 - 3 } $\begin{array}{l}\text { POVIDONE IODINE } \\
\text { N=60) }\end{array}$ & $18(30 \%)$ & $42(70 \%)$ & \\
\cline { 1 - 3 } TOTAL & $23(19.2 \%)$ & $97(80.8 \%)$ & \\
\hline
\end{tabular}

\section{TABLE:2}

\begin{tabular}{|c|c|c|}
\hline $\begin{array}{l}\text { SURGICAL SITE INFECTIONS } \\
\text { (SSI) } \\
\text { POSITIVE }\end{array}$ & $\begin{array}{l}\text { SURGICAL SITE } \\
\text { INFECTIONS (SSI) } \\
\text { NEGATIVE }\end{array}$ & P VALUE \\
\hline $14(14.9 \%)$ & $80(85.1 \%)$ & \\
\hline $9(34.6 \%)$ & $17(65.4 \%)$ & \\
\hline $23(19.2 \%)$ & $97(80.8 \%)$ & $.024 *$ \\
\hline
\end{tabular}

\section{Discussion}

The prevalence of surgical site infection in this study was $19.2 \%$. In those patients who received chlorhexidine alcohol, only $8.3 \%$ were developed SSI, where as those who received povidone iodine $30 \%$ of the patients were developed SSI. The Culture of surgical site in 23 infected patient yielded growth of organism. The organisms associated with SSI were staphylococus which constitute $11.7 \%$, streptococcus $0.8 \%$, e.coli $2.5 \%$, klebsiella 3.3\%, and pseudomonas constitute $0.8 \%$. No patients in our study group both group A and group B showed any adverse reactions to study agents. The nature of SSI in these 23 patients were superficial SSI, no one in both these group developed deep incisional infection/ organs space infection In these randomised study the SSIs using chlorhexidine alcohol was only $8.3 \%$ and found to be statistically significant. Although both the 
antiseptic preparations we studied possess broad-spectrum antimicrobial activity,[1] the superior clinical protection provided by chlorhexidine-alcohol is probably related to its more rapid action, persistent activity despite exposure to bodily fluids, and residual effect.[2] The superior clinical efficacy of chlorhexidine-alcohol in our study correlates well with previous microbiologic studies showing that chlorhexidine-based antiseptic preparations are more effective than iodine-containing solutions in reducing the bacterial concentration in the operative field for vaginal hysterectomy[3] and foot-and-ankle surgery.[4,5] Although the use of flammable alcohol-based products in the operating room poses the risk, though small, of fire or chemical skin burn, no such adverse events occurred in this study or the other studies.[3,5]

Chlorhexidine is a cationic biguanide that binds to the negatively charged surface of bacterial cell wall leading to alteration in permeability, which leads to leakage of cytoplasmic contents and finally cell death.[6] The residual effect; defined as the long-term antimicrobial suppressive activity; of chlorhexidine gluconate, is prolonged (at least $6 \mathrm{~h}$ ) while that of povidone-iodine is minimal. This prolonged residual effect of chlorhexidine is due to its adherence to the stratum corneum, which extends its duration of action for several hours after first application.[7] This ability of antiseptic solutions to bind to and penetrate the stratum corneum is important for effective clearance of the micro-organisms living by the side of the hair follicles or in the sebaceous glands. Up to $20 \%$ micro-organisms live deep within dermis and these may be an important source causing contamination of invasive devices and subsequent colonization.[8]

\section{Conclusion}

Pre-operative cleansing of the patients skin with chlorhexidine alcohol is superior to cleansing with povidone iodine for preventing surgical site infection after clean and clean contaminated elective surgery.

\section{References}

[1]. Mangram AJ, Horan TC, Peearson ML, Silver LC, Jarvis WR , Gulideline for prevention of surgical site infections. Hospital Infection Control Practices Advisory Committee.Infect Control Hosp Epidemiol 1999;20:250-278

[2]. Denton GW. Chlorhexidine. In: Block SS, ed. Disinfection, sterilization, and preservation. 5th ed. Philadelphia: Lippincott Williams \& Wilkins, 2001:321-36

[3]. Culligan PJ, Kubik K, Murphy M, Blackwell L, Snyder J. A randomized trial that compared povidone iodine and chlorhexidine as antiseptics for vaginal hysterectomy. Am J Obstet Gynecol 2005;192:422-425

[4]. Ostrander RV, Botte MJ, Brage ME. Efficacy of surgical preparation solutions in foot and ankle surgery. J Bone Joint Surg Am 2005;87:980-985

[5]. Bibbo C, Patel DV, Gehrmann RM, Lin SS. Chlorhexidine provides superior skin decontamination in foot and ankle surgery: a prospective randomized study. Clin Orthop Relat Res 2005;438:204-208

[6]. Milstone AM, Passaretti CL, Perl TM. Chlorhexidine: Expanding the armamentarium for infection control and prevention. Clin Infect Dis 2008;46:274-81

[7]. Hebl JR. The importance and implications of aseptic techniques during regional anesthesia. Reg Anesth Pain Med 2006;31:311-23.

[8]. Hebl JR, Niesen AD. Infectious complications of regional anesthesia. Curr Opin Anaesthesiol 2011;24:573-80. 